\title{
Improving the criteria for choosing the strategies in management by geotechnical systems
}

\author{
Yevhen Lapshyn ${ }^{1}$, Robert Molchanov ${ }^{2}$, Borys Blyuss ${ }^{1, *}$, and Nataliia Osadcha ${ }^{1}$ \\ ${ }^{1}$ Institute of Geotechnical Mechanics named by N. Poljakov of National Academy of Sciences of \\ Ukraine, 49005, Dnipro, Simferopolska Str., 2a, Ukraine \\ ${ }^{2}$ Dnepropetrovsk Medical Academy of the Ministry of Health of Ukraine, 49005, Dnipro, \\ Soborna Sq., 2, Ukraine
}

\begin{abstract}
The conclusion has been made about the necessity to choose the optimal strategies for management by geotechnical systems, based on the analysis of geological faults, which are the main indicator of the mining and geological conditions that characterize the mineral deposits, as well as on the parameters for the infrastructure development of the underground space. The methodological peculiarity of solving the problems set is the use of game theory with modified criteria of Wald, maximax and Savage, since the manifestation of specific geological faults is probabilistic in nature. When choosing the optimal strategy, the average linear deviations of gains or risks are taken into account.
\end{abstract}

\section{Introduction}

At present, the geological faults, which characterize the conditions for the development of mineral deposits, determine the choice of technical means and technological solutions.

According to the time of formation and the nature of impact on the seams, the main geological faults can be represented in the following groups: tectonic disjunctive dislocations with seams fracturing; tectonic plicative, causing the curvature of the seams boundaries; dislocations of sedimentation character, which reflect the changes in the structure and thickness of the seams, their bottom and roof [1].

The dislocation with a break in continuity - this is a discontinuity of mine rocks along a certain surface, accompanied by the rock blocks movement relative to each other. The dislocations with a break of continuity are characterized by such effects as fracture, rupture, disjunctive (rupture) dislocation, disjunctive break, rupture displacement, tectonic rupture. The dimensions of dislocations with a break of continuity vary in the range: the extent from meters to thousands of kilometres, the value of rocks displacement - from centimetres to hundreds of kilometres. In this regard, local, regional, crustal and general planetary faults are distinguished, which differ in length, value of displacement and geological significance.

\footnotetext{
*Corresponding author: bblyuss@gmail.com
} 
It should be noted that the most widespread is the morphological classification of dislocations with a break in continuity based on the characteristics: the direction of the relative displacement of the fault wings, the direction and incidence angle of the fault plane. According to these signs, the following groups of discontinuity structures are distinguished: normal faults, expansions, reverse faults, thrusts and lags. This classification divides the faults into those formed under conditions of compression (reverse faults, thrusts, lags) or of stretching (normal faults, expansions) of the earth's crust.

The effectiveness of accepted technological decisions, depending on the probability of a specific geological fault, determines the choice of the optimal strategy for management by geotechnical systems. And this is reflected in the elements of a certain matrix, the interpretation of which is possible based on the methodology of game theory.

The necessity to make decisions based on game theory is determined by a set of criteria and well-known tooling when planning the mining operations and managing the technological processes in mining enterprises [2 - 8].

\section{Main part}

Let us consider the problem of decision-making under the conditions of indeterminacy [5, 11-13]. The indeterminacy means the absence or lack of information about the possible manifestation of geological faults [9]. In this case, it is advisable to use a mathematical model 'Game with Nature'. In the game, a conscious 'player' is a decision-making person (DMP), and 'nature' is a geotechnical system (natural environment). At the same time there is no information about the probabilities of the state of nature.

It is assumed that the player has $m$ of strategies $\left(A_{1}, \ldots, A_{m}\right)$, and the nature has $n$ of possible states $\left(\Pi_{1}, \ldots, \Pi_{n}\right)$. The 'gains' $a_{i j}$ are known of a player at $i$ of a strategy and $j$ of a state of nature. A set of elements $a_{i j}$ form a matrix of game $A$ with size $m \times n$.

In order to choose the optimal strategy, the following classical criteria are used: maximin Wald, maximax and Savage. However, they do not take into account the distribution of all the gains and risks in the different states of nature.

The objective of work is to improve the criteria by taking into account the influence of possible states of nature - geological faults on the choice of management strategy.

\subsection{Wald criterion}

The Wald criterion (criterion of guaranteed result, criterion of pessimism) is one of the most important criteria for reliable decision-making [5, 11-13]. It is also used in a number of composite criteria: Hurwitz, Hodges-Lehmann and Germeyer-Hurwitz.

The application area of Wald criterion:

- nothing is known about the probabilities of states of nature;

- risk is not allowable;

- only a small number of solutions is realizable.

The Wald criterion is calculated by the formula

$$
W=\max _{i} \min _{j} a_{i j}
$$

For each strategy $A_{i}$, we perform a repositioning (ranking) of gains $a_{i j}$, arranging them in a non-decreasing order $[11,12]$. The elements of the obtained matrix are denoted by $b_{i j}$, and the matrix itself by $B$.

Thus, in each $i$-th row of the matrix $B$ we have: 


$$
b_{i 1} \leq b_{i 2} \leq \ldots \leq b_{i m}
$$

By virtue of the ratio (1), the first column consists of the minimum gains

$$
b_{i 1}=\min _{j} a_{i j} .
$$

Hence, the Wald criterion

$$
W=\max _{i} b_{i 1}=\max _{i} \min _{j} a_{i j} .
$$

The strategy for which the Wald criterion is valid, will be denoted by $A_{W}$.

In addition to the traditional approach, we will introduce into consideration the allowable interval for the Wald criterion

$$
W_{\min } \leq W
$$

where $W_{\min }$ - the low limit of the Wald criterion, acceptable to DMP.

In case of the strategies $A_{i}$ existence, for which $b_{i 1}$ is within the interval $\left[W_{\min }, W\right]$, it is possible to choose a strategy better than $A_{W}$. To do this, we determine the increment in gain compared with the minimum possible

$$
\delta_{i j}=b_{i j}-b_{i 1} .
$$

The averaged increment of gain for $i$-th strategy is characterized by the average linear deviation relative to $b_{i 1}$

$$
\bar{\delta}_{i}=\frac{1}{m-1} \sum_{j=2}^{m} \delta_{i j} .
$$

When comparing the two strategies, the strategy is more favourable that provides the higher averaged increment.

\subsection{Maximax criterion}

The maximax criterion (optimism criterion) is calculated according to the dependence

$$
M=\max _{i} \max _{j} a_{i j} .
$$

It follows from the ratio (1) that the last column in the matrix $B$ consists of the maximum gains. In this regard, the criterion $M$ can be written in this form

$$
M=\max _{i} b_{i m} .
$$

Let us introduce into consideration the allowable interval for the maximax criterion

$$
M_{\min } \leq M
$$

where $M_{\min }$ - the low limit of the criterion, acceptable to DMP.

The strategy corresponding to the criterion $M$ is denoted by $A_{M}$. 
For the strategies $A_{i}$, at which $b_{i m} \in\left[M_{\min }, M\right]$ the choice is possible of better than $A_{M}$. For this purpose, we determine the decrease in gain as compared with the maximum possible

$$
\Delta_{i j}=b_{i m}-b_{i j} .
$$

The averaged decrease in gain for the $i$-th strategy will be described by means of the average linear deviation relative to $b_{i m}$

$$
\bar{\Delta}_{i}=\frac{1}{m-1} \sum_{j=2}^{m} \Delta_{i j}
$$
$\bar{\Delta}_{i}$

Of the two strategies, preference should be given to that one, which has a lower value of

To the right side of (3) we add and subtract $b_{i 1}$, and then having performed grouping we obtain

$$
b_{i m}-b_{i j}=\left(b_{i m}-b_{i 1}\right)-\left(b_{i j}-b_{i 1}\right)
$$

Given that $\delta_{i j}=b_{i j}-b_{i 1}$, we will obtain the dependence between the average linear deviations

$$
\bar{\Delta}_{i}=\frac{m}{m-1}\left(b_{i m}-b_{i 1}\right)-\bar{\delta}_{i}
$$

The formula (5) can be used to verify the obtained values of $\bar{\Delta}$ and $\bar{\delta}_{i}$.

Example. Game model matrix

$$
A=\left(\begin{array}{cccc}
6.0 & 13.6 & 12.0 & 9.0 \\
8.0 & 13.0 & 14.0 & 6.8 \\
10.0 & 7.0 & 11.0 & 10.0
\end{array}\right),
$$

Where gains are in conventional units. Having performed the ranking, we obtain

$$
B=\left(\begin{array}{cccc}
6.0 & 9.0 & 12.0 & 13.6 \\
6.8 & 8.0 & 13.0 & \underline{\underline{14.0}} \\
\underline{7.0} & 10.0 & 10.0 & 11.0
\end{array}\right) .
$$

The first column of the matrix $B$ consists of minimal elements. The maximum of them is $b_{31}=7$ (underlined by a single line), therefore, by Wald criterion, the third strategy is optimal. Suppose that for DMP it is permissible to reduce the gain by 0.5 . Since 6.8 is in the interval of 6.5-7, then we will compare the strategies $A_{2}$ and $A_{3}$ according to the average linear increments. The calculations by the formula (2) gave the result $\bar{\delta}_{2}=4.87$ and $\bar{\delta}_{3}=3.33$, i.e., $\bar{\delta}_{2}>\bar{\delta}_{3}$. Thus, it is rational to choose the second strategy.

If DMP is focused on an optimistic result, then according to the maximax criterion $M=b_{23}=14$ (underlined by a double line) - the second strategy is optimal. Let the former 
value of the decrease in gain is allowable, as $13.6 \in[13,5,14]$, then, having compared the strategies $A_{1}$ and $A_{2}$ according to average linear increments, by the formula (4), we will obtain $\bar{\Delta}_{1}=4.6$ and $\bar{\Delta}_{2}=4.73$, i.e., $\bar{\Delta}_{1}<\bar{\Delta}_{2}$. From which it follows that it is rational to choose the first strategy.

\subsection{Savage criterion}

The Savage criterion is similar to the strategy choice by the Wald criterion, but DMP is guided by a risk matrix $R$, the elements of which are calculated by the formula

$$
r_{i j}=\alpha_{j}-\alpha_{i j},
$$

where $a_{j}=\max _{i} a_{i j}, j=1,2, \ldots, n, i=1,2, \ldots, m$.

The elements $r_{i j}$ characterize the value of losses.

The criterion of minimum risk by Savage $[3,4,13]$

$$
S=\min _{i} \max _{j} r_{i j}
$$

For all $A_{i}$ strategies, we will reposition the risks $r_{i j}$ in non-decreasing order. The obtained matrix is denoted by $H$, and its elements by $h_{i j}$. The last column $h_{i n}$ consists of maximum risks. This make possible to write the Savage criterion in the following form

$$
S=\min _{i} h_{i n} .
$$

Let the allowable interval for the Savage criterion is

$$
S_{\max } \geq S,
$$

where $S_{\max }$ - the upper limit of the criterion, acceptable to DMP.

For strategies $A_{i}$, which have $h_{i m} \in\left[S, S_{\max }\right]$, the choice is possible of better than $A_{S}$. For this purpose, we determine the decrease in risk as compared with the maximum possible

$$
\Delta h_{i j}=h_{i m}-h_{i j} .
$$

The averaged decrease in risk for the $i$-th strategy is characterized by the average linear deviation relative to $h_{i m}$

$$
\bar{\Delta} h_{i}=\frac{1}{m-1} \sum_{j=1}^{m} \Delta h_{i j} .
$$

The strategy should be chosen that provides a greater decrease in risk.

Example. The matrix of gains is given

$$
A=\left(\begin{array}{llll}
1.2 & 4.0 & 4.7 & 6.0 \\
3.0 & 3.3 & 7.0 & 3.0 \\
4.0 & 4.8 & 6.0 & 2.0
\end{array}\right)
$$


We calculate the risk matrix by the formula (6)

$$
R=\left(\begin{array}{llll}
2.8 & 0.8 & 2.3 & 0.0 \\
1.0 & 0.6 & 0.0 & 3.0 \\
0.0 & 0.0 & 1.0 & 4.0
\end{array}\right)
$$

Let us perform the ranking by the matrix $R$ rows

$$
H=\left(\begin{array}{llll}
0.0 & 0.8 & 2.3 & \mathbf{2 . 8} \\
0.0 & 0.6 & 1.0 & 3.0 \\
0.0 & 0.0 & 1.0 & 4.0
\end{array}\right) .
$$

According to the Savage criterion (7), which is equal to 2.8 (it is in bold in the matrix), the first strategy should be chosen. Let the allowable increase in the risk is by 0.5 . This condition is satisfied by the second strategy. The calculations by (9) gave the following result: $\bar{\Delta} h_{1}=1.77$ and $\bar{\Delta} h_{2}=2.47$. Since $\bar{\Delta} h_{1}<\bar{\Delta} h_{2}$, then it is rational to choose the second strategy.

\section{Conclusions}

The disadvantage of the Wald, maximax and Savage criteria is that they do not take into account all the states of nature - possible geological faults. In order to avoid this disadvantage, it is proposed, when choosing the optimal strategy, in addition to take into account the average linear deviations of gains or risks that characterize the effectiveness of management by geotechnical systems.

\section{References}

1. Mineev , S.P., Rubinskiy, A.A., Vitushko, O.V., Radchenko, A.G. (2010). Gornyie rabotyi $v$ slozhnyih usloviyah na vyibrosoopasnyih ugolnyih plastah. Donetsk: Shidniy vidavnichiy dim

2. Taha, Hemdi (2005). Vvedenie v issledovanie operacij. Moskva: Izdatel'skij dom "Vil'yams"

3. Shiyan, A.A. (2009). Teoriya igor: osnovi ta zastosuvannya $v$ ekonomici ta menedzhmenti. Vinnicya: VNTU

4. Petrushenko, M.M. (2012). Economic "games against nature": a model for decisionmaking in the field of environmental conflict management. Biznes Inform, 4, 130-132

5. Shapkin, A.S., Shapkin, V.A. (2005). Teoriya riska i modelirovanie riskovyh situacij. Moskva: Izdatelsko-torgovaya korporaciya «Dashkov \& $\mathrm{C}^{0} »$

6. Shubik, M. (2012). The present and future of game theory. Matematicheskaya teoriya igr i ee prilozheniya [Mathematical game theory and its applications], 4, 1, 93-116

7. Kaluski, Ya. (2011). Application of game theory in the planning and management of mining enterprise resources, Komp'yuting [Computing], 10, 2, 172-178

8. Bulat, A.F., Bun'ko, T.V., Kokoulin, I.Ye., and Yashchenko, I.A. (2017). The criteria for use of a risk matrix for the improvement of production management system and occupational safety and health in coal mines. Geotehnicheskaya mehanika [GeoTechnical Mechanics], 133, 228-238

9. Information Services (2011). Indeterminacy, available at: https://ru.wikipedia.org 
10. Vil'chek, F. (2016). Krasota fiziki: Postigaya ustroystvo prirody. Moskva: Al'pina nonfikshn

11. Labsberg, L.G., Yanovskai, E.V. (2002). General methodology for constructing criteria for optimal solutions in the conditions of risk and uncertainty, Upravleniye riskom [Risk management], 4, 13-24

12. Labsberg, L.G. (2009). On the indicator of optimism of a person making a decision on the Generalized Hurwitz criterion. Ekonomicheskiye nauki [Economics], 53, 305-312

13. Mikhaelis, V.V. (2016). The application of some criteria for the selection of the optimal strategy in game theory. Informatsionnyye tekhnologii $i$ problemy modelirovaniya slozhnykh system [Information technologies and problems of modeling complex systems]. Irkutsk: IrGUPS, 15, 89-95 